\title{
Smart Factories from Business, Management and Accounting Perspective: A Systemic Analysis of Current Research
}

\author{
ANDREJ JERMAN \\ Ljubljana Passenger Transport, Slovenia \\ andrejjerman1@gmail.com \\ GANDOLFO DOMINICI \\ University of Palermo, Italy \\ gandolfo.dominici@libero.it
}

The primary purpose of this study is to investigate to what extent smart factories have been addressed in the research in the business, management and accounting field and to identify possible gaps in the current research. The bibliographic units from the Scopus database on the keyword 'smart factory,' limited to the business, management and accounting research field was searched. In order to answer research questions, a bibliometric analysis and the data mining was performed. From the text of founded articles, gaps in the current research were searched in order to provide guidance for future research directions. There is a growing trend on the smart factory topic, but they are mostly connected with the field of engineering, decision-making, or computer science. Fields most explored are management of supply chains, changes in business models, individualization of production system and business processes optimization. The important gap is the lack of studies in the field of human resources management.

Key words: smart factory, literature review, management, content analysis, systematic analysis

https://doi.org/10.26493/1854-4231.13.355-365

\section{Introduction}

In Germany, a new concept of economic policy called 'Industry 4.0' was developed in 2011, based on high-tech strategies (Mosconi 2014). The concept posits a fourth industrial revolution based on concepts and technologies that include Cyber-Physical Systems (сPS), the Internet of Things (гот), and the Internet of Services (IoS) (Möller 2016). Industry 4.0 is currently one of the most discussed topics in both the academic and business worlds (Foidl and Felderer 2016). The three key components of Industry 4.0 are cyber-physical 
systems (links between the virtual in the virtual world), the IoT, and the IoS (Dominici et al. 2016). Such new concepts force companies to transform their traditional business models into digital business models, which presents a huge challenge for these companies. New business model involves 'the virtualisation and vertical and horizontal integration of the value chain, digital services, the digital transformation of products, production equipment, factories and supply chains' (Cozmiuc and Petrison 2018).

As for Industry 4.0, we cannot limit ourselves to thinking of robotics in automation of production, because it is the digitization of business processes as a whole; it involves adapting processes in the purchase of raw materials and how the product travels through production and is finally delivered to the customer. In this area, we expect the automation of processes, which requires certain automation of work. Value added will arise from new products and new solutions (Kane et al. 2015). Industry 4.0 creates what is called a 'smart factory.'

Smart factories are one of the critical components of Industry 4.o. Gilchrist (2016), Ghobakhloo (2018), Liao et al. (2017), Santos et al. (2017), Ustundag and Cevikcan (2017), Vogel-Heuser and Hess (2016) believe that Industry 4.0 can be defined based on two categories: its principles of design and its technological trends. The principles of design represent the systematisation of knowledge and a description of the components that are an integral part of Industry 4.o (Hermann, Pentek, and Otto 2016). These enable key stakeholders to monitor the progress of Industry 4.0 and help them to choose the appropriate procedures and solutions needed for the continued transition to Industry 4.o. Technological trends are related to advance digital technology innovations, which together enable the emergence of a new digital industry, i.e., Industry 4.o (Gilchrist 2016; Liao et al. 2017). Industry 4.0, as an integrative value creation system, consists of 12 principles of design, including virtualisation, decentralisation, modularity, interoperability, smart products, smart factories, etc. and 14 technological trends, including block chain technology, Internet of thing, Internet of services, cyber-physical systems, etc. Smart factories are therefore placed in the principles of design, the component of Industry 4.0 (Ghobakhloo 2018).

A smart factory is the main feature of Industry 4.0 and is characterised 'by self-organised multi-agent systems assisted with Big Data-based feedback and coordination' (Russell and Norvig 2009). A smart factory can develop products virtually; in current times, companies can run virtual experiments on a digital prototype. Within the 
modular structured, smart factories, cyber-physical systems monitor physical processes, create virtual copies of the physical world, and make decentralised decisions. Via the IoT, cyber-physical systems communicate and cooperate with each other and with people in real-time both internally and across organisational services offered and used by participants of the value chain (Flynn, Dance, and Schaefer 2017). As such, digital manufacturing and design are influencing careers, practices, and processes in companies (Crnjac, Veža, and Banduka 2017).

In this paper, the we discuss the smart factory concept, whose main features are a transformation away from paper-based processes to a digital continuum, the transformation of the way products are designed and manufactured, and transformation from conventional business models to smart, digital models (Russel and Norvig 2009). The goal of this paper is to determine to what extent the smart factories are addressed in business, management and accounting research, to reveal research areas on the topic of smart factories and to identify gaps in the current research in order to provide guidance for future research directions.

The concept of the smart factory is mainly discussed from a technical point of view (Sinsel et al. 2017), while the management, especially soft factors of the organization's management, in our opinion, is not addressed enough in research literature. For this reason, the goal of the paper is an analysis of literature dealing with smart factories from business, management, and accounting aspect.

The paper is structured as follows: it starts with the definitions of the concept of a smart factory, as have been given by different authors. The third section present systemic analysis. Finally, the primary research results have been presented and discussed, conclusions and gaps are identified.

The following research questions were set for the purpose of the study:

RQ1 To what extent the smart factories have been addressed in the research in the business, management and accounting field and with which fields they are mostly connected?

$\mathrm{RQ} 2$ Which are the research gaps?

\section{Research Methodology}

The largest bibliographic database, Scopus database, was included in the study. The bibliographic units on keyword smart factory or factory of future limited by business research area ((ALL ('smart fac- 


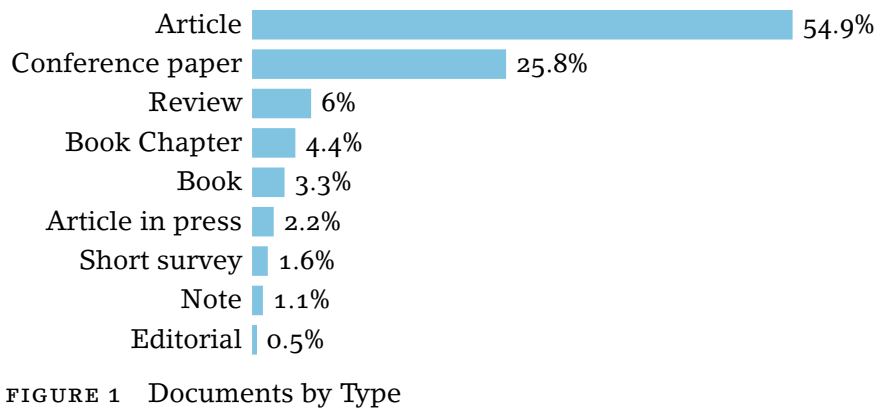

tory') AND (LImit-To (subAREA, 'BUSI')) were covered. No other inclusion or exclusion criteria were used. This approach retrieved 182 papers (conference papers, journal papers, book chapters) of all year timespan.

In the first step, bibliometric analysis was performed with the help of Scopus analysis services. Publication years, types of publications, publication sources, research areas, most frequent authors, authors' affiliations and authors' country were presented. For performing word phrase analysis, software Provalis Wordstat 8.0 was used. To shed light on smart factory research trends, a statistic review was conducted to identify possible gaps in the current research in order to provide guidance for future research directions.

\section{Results and Discussion}

A total number of 182 contributions were found from the Scopus database. The first two contributions on smart factories in business, management and accounting area were detected in the year of 1990 and 1996. In 1990, 1996, 2003, 2004, 2006, 2009, 2010 and 2011 there was one contribution on this topic each year. In 2007 three contributions were detected. Since the Industry 4.0 concept, with the aim to establish smart factories, was first announced at the Hannover Messe 2011 in Germany, a slight increase in the number of contributions in this research area, from the year 2011 to 2014, is noticed. The number of contributions has been increasing dramatically since 2015.

From analysed contributions 104 (57.1\%) were published as journal articles, $47(25.8 \%)$ as conference papers in conference proceedings, $11(6 \%)$ as reviews, $8(4.4 \%)$ as book chapters, $6(3.3 \%)$ as books, $3(1.6 \%)$ as short surveys, 2 as notes, and 1 as editorial (Figure 1 ).

Top eight institutions publishing on the topic of smart factory in the business field are Rheinisch-Westfalische Technishe Hochschu- 
TABLE 1 Number of Documents by Research Areas

\begin{tabular}{lrr}
\hline Reserch area & $f$ & $\%$ \\
\hline Business, management and accounting & 182 & 100,0 \\
Engineering & 120 & 65,9 \\
Decision science & 87 & 47,8 \\
Computer science & 47 & 25,8 \\
Mathematics & 22 & 12,1 \\
Energy & 16 & 8,8 \\
Economic, econometrics and finances & 15 & 8,2 \\
Environmental science & 10 & 5,5 \\
Material science & 10 & 5,5 \\
Social science & 6 & 3,3 \\
Others & 13 & 7,1 \\
\hline
\end{tabular}

TABLe 2 The Most Often Used Phrases in Papers

\begin{tabular}{ll}
\hline Smart factory & Production processes \\
Supply chain & Manufacturing system \\
Cyber physical & Industrial revolution \\
Internet of Things & Case study \\
Production systems & Manufacturing companies \\
\hline
\end{tabular}

le, Politecnico di Milano, Hochschule für Wirtschaft und Recht Berlin, Seoul National University, Friedrich-Alexander-Universität Erlangen-Nürnberg, Technische Universitat Braunschweig, Helmut Schmidt University, and University of Cambridge with three or more publications.

Bibliometric analysis on smart factories in order to examine research areas of the contributions was performed. Most of the selected contributions were grouped into categories of engineering, decision science, and computer science, in addition to business, management and accounting.

The largest number of authors is from Germany, which is to be expected, since the concept started in Germany, followed by Italy and United States (Figure 2). The most frequent authors, publishing in the field of smart factory are Ivanov with five contributions, Kletti, Rauch, Sanders, Teresko and Wulfsberg, all with three contributions.

Provalis Wordstat 8.0 program was used to perform a word phrase analysis, which was used in order to enable better understanding of contributions titles. Table 2 shows the most often used phrases in paper titles, followed by phrases 'smart factory,' 'supply chain,' 'cyber physical,' 'Internet of things,' and 'production systems.' Table 3 


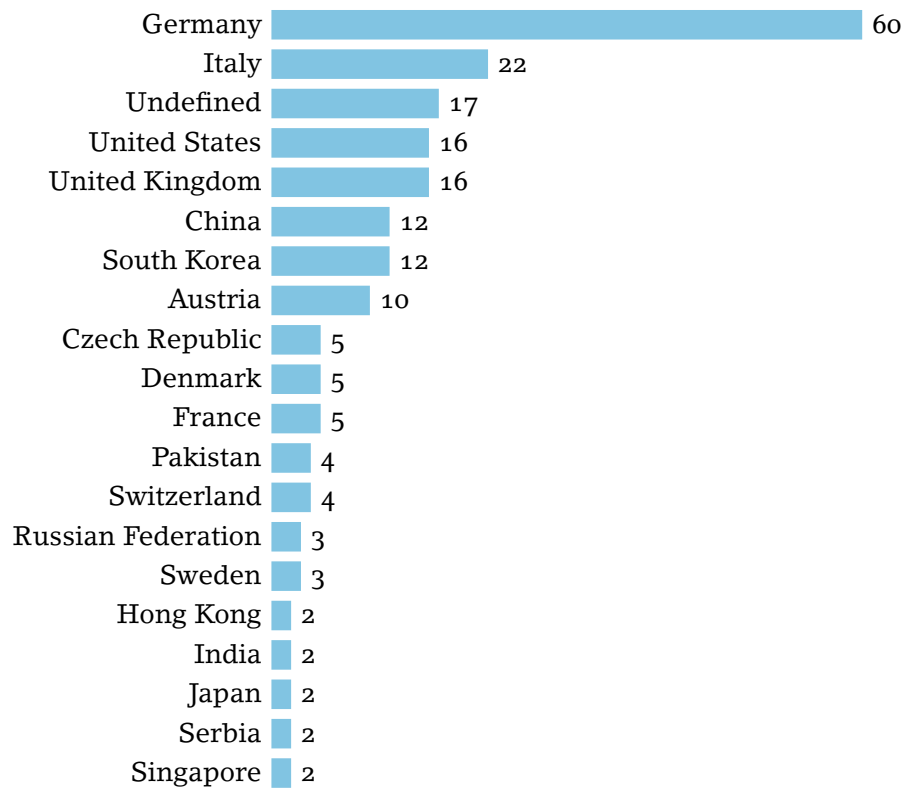

FIGURE 2 Most Frequent Authors' Country

TABLE 3 The Most Commonly Used Words in the Titles

\begin{tabular}{lrlr}
\hline Word & $f$ & Word & $f$ \\
\hline 4.0 & 14 & Management & 10 \\
Assessment & 5 & Manufacturing & 13 \\
Energy & 5 & Production & 6 \\
Factory & 7 Smart & 11 \\
Industry & 13 Systems & 5 \\
\hline
\end{tabular}

presents most commonly used words in titles of contributions, which were extracted using word list analysis by Atlas.ti program.

In order to answer the second research question, we used cluster analysis of the phrases using Provalis Wordstat version 8.o. Cluster analysis of phrases was conducted using of average-linkage hierarchical clustering algorithm, which creates clusters from a similarity matrix (Everitt et al. 2011).

Figure 3 presents the results of the cluster analysis that identified ten groups of topics regard smart factories, i.e.:

- cluster 1 includes abstracts, with the words analysis and framework,

- cluster 2 includes abstracts with the words factory, smart, and time, 


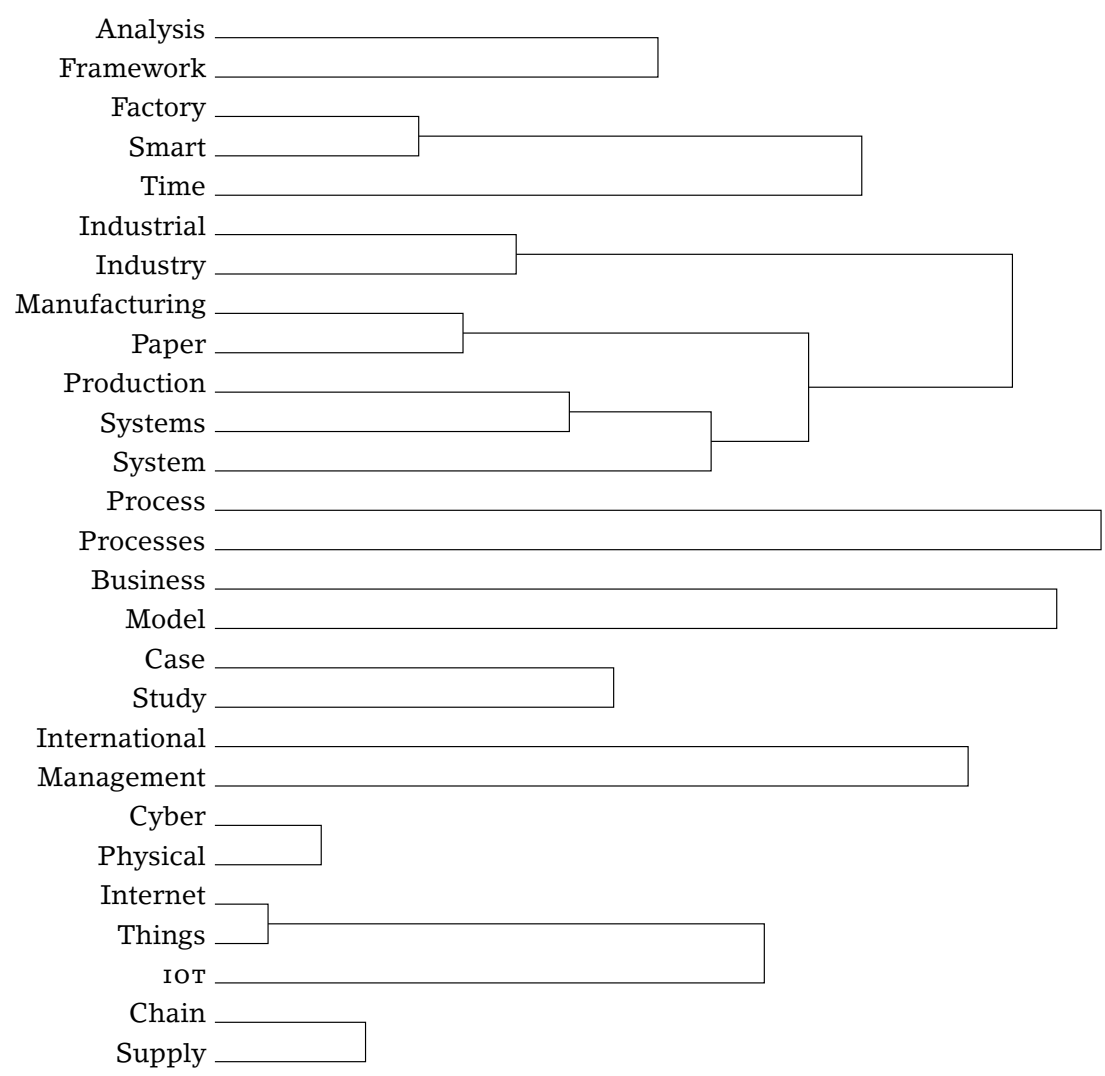

FIgURE 3 Cluster Analysis of Phrases Related to Smart Factories

- cluster 3 includes abstracts with the words industrial, industry, manufacturing, paper, production, systems, and system,

- cluster 4 includes abstracts with the words process and processes,

- cluster 5 includes abstracts with the phrases business and model,

- cluster 6 includes abstracts with the words case and study,

- cluster 7 includes abstracts with the words international and management,

- cluster 8 includes abstracts with the words cyber and physical,

- cluster 9 includes abstracts with the words internet things, and IoT, and

- cluster 10 includes abstracts with the words chain and supply.

We used proximity plots in order to detect phrases that tend to frequently appear near phrase smart factory or smart factories in 
the abstracts. The phrases that occur the most often with the phrase smart factory, such as cyber physical and system, time and Internet of Things (IoT), are mostly related to the definition of the smart factory. The phrases that also occur often with the phrase smart factory are related to methods and techniques for data gathering such as case study, analysis framework.

The phrases that occur the most often with the phrase smart factory, and answer the research question 2, indicate its's specific research areas such as supply chain, business model, processes, industrial production (manufacturing) system. Four main lines of research related to business, management and accounting therefore appear in the literature of smart factories: (1) supply chain management, (2) redesign of business models and value creation through new business model, (3) production system (product equipment, product design), and (4) redesign of business processes (process optimization and digitalization).

After we read full texts of all 182 contributions, we could assume that most of them deals with the topic of supply chain management, for instance with interconnections of cross-company supply chains (Bauer, Herkommer, and Schlund 2015), opportunities for circular supply chains (Tsolakis, Kumar, and Srai 2016), supply chain dynamics (Ivanov, Mason, and Hartl 2016), sustainable supply chains (Bechtsis et al. 2017), followed by value creation through new business model (Schneider, Mittag, and Gausemeier 2016), product individualization (Emmelmann, Rudolph, and Herzog 2017), and business process optimization (Yin, Stecke, and Li 2017).

Production paradigms are and have always been shaped by different factors, i.e. sociological, economic and technological (Chu et al. 2016). Sinsel et al. (2017) and Magone (2016) found that the main perspective in Industry 4.0 is a technological perspective. A few studies on the economic valuation of smart factories exist, such as cost-effectiveness analysis (Sinsel et al. 2017) and studies on the productivity of smart factories (Madsen and Mikkelsen 2018; Munyai, Mbonyane and Mbohwa 2017). The aim of smart factories is not only to create an economic effect, such as reducing costs and increasing productivity, but also to consider human and the sociological aspect of the new paradigm brought by the fourth industrial revolution (Kang et al. 2016).

\section{Conclusion}

In this paper, we discuss the concept of smart factory, which main features are transformation away from paper-based processes to 
digital continuum, transformation of the way the product are designed and manufactured, and transformation from classic business model to smart, digital model. The main aim of the study is to investigate to what extent the smart factories have been addressed in the research in the business, management and accounting field. To achieve this aim, we performed systematic analysis of the bibliographic units from Scopus database on keyword smart factory or factories of the future and analysed 182 contributions on the topic smart factory. The analysis provided insights into the area of business, management and accounting.

The increasing trend in research from this field is present from 2011. In our research, it was found that research on smart factory in business, management and accounting field are interdisciplinary and are mostly connected with the fields of engineering, decision and computer science. Most of the contributions deals with the topic of supply chain management, business model, production system and business processes.

The paper contributes to a better understanding of research on the smart factory subject, which is not only valuable for academia, but also for factories facing changes of the business model and business processes. Finding of the systemic analysis can be used as the basis for future research in this field. While we believe our study has an important contribution, it has some limitations, for example that we only looked at articles from the database of the Scopus and that the searching was limited to peer-reviewed literature written in English. Future studies on smart factories should therefore also include other databases and literature in other languages.

\section{References}

Bauer, W., O. Herkommer, and S. Schlund. 2015. 'Die Digitalisierung der Wertschöpfung kommt in deutschen Unternehmen an: Industrie 4.0 wird unsere Arbeit verändern.' zwF Zeitschrift für wirtschaftlichen Fabrikbetrieb 110 (1-2): 68-73.

Bechtsis, D., N. Tsolakis, D. Vlachos, and E. Iakovou. 2017. 'Sustainable Supply Chain Management in the Digitalisation Era: The Impact of Automated Guided Vehicles.' Journal of Cleaner Production 142:3970-84

Chu, W. S., M. S. Kim, K. H. Jang, J. H. Song, H. Rodrigue, D. M. Chun, ... and S. Min. 2016. 'From Design for Manufacturing (DFM) to Manufacturing for Design (MFD) via Hybrid Manufacturing and Smart Factory: A Review and Perspective of Paradigm Shift.' International Journal of Precision Engineering and Manufacturing-Green Technology 3 (2): 209-222. 
Cozmiuc, D., and I. Petrisor. 2018. 'Industrie 4.0 by Siemens: Steps Made Next.' Journal of Cases on Information Technology 20 (1): 31-45.

Crnjac, M., I. Veža, and N. Banduka. 2017. 'From Concept to the Introduction of industry 4.o.' International Journal of Engineering and Management 8 (1): 21-30.

Dominici, G., V. Roblek, T. Abbate, and M. Tani. 2016. 'Click and Drive: Consumer Attitude to Product Development: Towards Future Transformations of the Drivingexperience.' Business Process Management Journal 22 (2): 420-34.

Emmelmann, C., J. P. Rudolph, and D. Herzog. 2017. 'Bauteilbewertung in der Cloud.' zwF Zeitschrift für wirtschaftlichen Fabrikbetrieb 112 (11): 802-5.

Everitt, B. S., S. Landau, M. Leese, and D. Stahl. 2011. 'Hierarchical clustering.' In Cluster Analysis, 71-110. 5th ed. Chichester: Wiley.

Flynn, J., S. Dance, and D. Schaefer. 2017. 'Industry 4.0 and its Potential Impact on Employment Demographics in the uk.' Advances in Transdisciplinary Engineering 6:239-44.

Foidl, H., and M. Felderer. 2016. 'Research Challenges of Industry 4.0 for Quality Management.' Lecture Notes in Business Information Processing 245:121-37.

Ghobakhloo, M. 2018. 'The Future of Manufacturing Industry: A Strategic Roadmap Toward Industry 4.o.' Journal of Manufacturing Technology Management 29 (6): 910-36.

Gilchrist, A. 2016. Industry 4.o: The Industrial Internet of Things. Heidelberg: Springer.

Hermann, M., T. Pentek, and B. Otto. 2016. 'Design Principles for Industry 4.0 Scenarios.' Paper presented at the 49th Hawaii International Conference on System Sciences, Kauai ${ }_{s}$ 5-8 January.

Ivanov, D., S. J. Mason, and R. Hartl. 2016. 'Supply Chain Dynamics, Control and Disruption Management.' International Journal of Production Research 54 (11): 3397-413.

Kane, G. C., D. Palmer, A. N. Phillips, and D. Kiron. 2015. 'Is Your Business Ready for a Digital Future?' міт Sloan Management Review 56 (4): 37-44.

Kang, H. S., J. Y. Lee, S. Choi, B. H. Kim, and S. D. Noh. 2016. 'Smart Manufacturing: Past Research, Present Findings, and Future Directions.' International Journal of Precision Engineering and Manufacturing - Green Technology 3 (1): 111-28.

Liao, Y., F. Deschamps, E. D. F. R. Loures, and L. F. P. Ramos. 2017. 'Past, Present and Future of Industry 4.0: A Systematic Literature Review and Research Agenda Proposal.' International Journal of Production Research 55 (12): 3609-29.

Madsen, E. S., and L. L. Mikkelsen. 2018. 'The Need of Knowledge Modification in Technology Change.' Production, Planning and Control 29 (2): 91-105 
Magone, A. 2016. 'Technology and the Human Factor in the Digital Factory.' Industria 37 (3): 407-26.

Mosconi, F. 2014. The New European Industrial Policy: Global Competitiveness and the Manufacturing Renaissance. London: Routledge.

Möller, D. P. F. 2016. Guide to Computing Fundamentals in Cyber-Physical Systems. Heidelberg: Springer.

Munyai, T. T., B. L. Mbonyane, and C. Mbohwa. 2017. Productivity Improvement in Manufacturing smes: Application of Work Study. Abingdon: Taylor \& Francis.

Russell, S. J., and P. Norvig. 2016. Artificial intelligence: A Modern Approach. Boston, mA: Pearson Education.

Santos, C., A. Mehrsai, A. C. Barros, M. Araújo, and E. Ares. 2017. 'Towards Industry 4.0: An Overview of European Strategic Roadmaps.' Procedia Manufacturing 13:972-9.

Schneider, M., T. Mittag, and J. Gausemeier. 2016. 'Modeling Language for Value Networks.' Paper presented at the 25th International Association for Management of Technology Conference, Orlando, FL, 15-19 May.

Sinsel, A., C. Bangert, J. Stoldt, and T. Buttner. 2017. 'Economic Evaluation of the Smart Factory - An Approach to the Assessment of Digitalization in Production.' zwF Zeitschrift für wirtschaftlichen Fabrikbetrieb 112 (9): 602-6.

Tsolakis, N., M. Kumar, and J. S. Srai. 2016. 'Exploring Opportunities for Circular Supply Chains Arising from Renewable Chemical Feedstocks.' Paper presented at the or58 Annual Conference, Portsmouth, 6-8 September.

Ustundag, A., and E. Cevikcan. 2017. Industry 4.o: Managing The Digital Transformation. Hidelberg: Springer.

Vogel-Heuser, B., and D. Hess. 2016. 'Guest Editorial Industry 4.0: Prerequisites and Visions.' If ex Transactions on Automation Science and Engineering 13 (2): 411-3.

Yin, Y., K. E. Stecke, and D. Li. 2018. 'The Evolution of Production Systems from Industry 2.0 through Industry 4.o.' International Journal of Production Research 56 (1-2): 848-61. 